\title{
Catching the runner's high: Anxiety and the endocannabinoid system
}

\section{Keith Semler, DO}

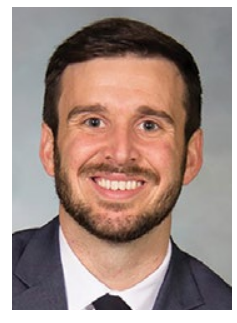

Dr. Semler is a PGY-2 Psychiatry Resident, Department of Psychiatry, AtlantiCare Regional Medical Center, Atlantic City, New Jersey.

\section{Disclosure}

The author reports no financial relationships with any companies whose products are mentioned in this article, or with manufacturers of competing products.

doi: 10.12788/cp.0190

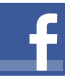

Discuss this article at www.facebook.com/ MDedgePsychiatry
$\mathrm{E}$ ffortless." "Weightless." "Limitless." "Carefree." In most cases, these are words one would not commonly associate with running. In fact, many people might experience an uptick in anxiety when fathoming the idea of going out for a run. Believe it or not, these words are direct quotes from runners describing the feeling of a "runner's high" - a well-documented organic euphoria that cannot be purchased or abused. But how is the innately basic and monotonous act of running able to reliably transform something as complex as human emotion? This answer lies in the endocannabinoid system.

For decades, scientists and the public believed the runner's high was associated with an exercise-induced increase in levels of opioid peptides called beta-endorphins. The problem with this theory is that betaendorphin, released into the blood by the pituitary gland in response to exercise and stress, has difficulty passing through the blood-brain barrier, rendering central effects of this peripheral opioid unlikely. ${ }^{1}$ Only recently have researchers been examining the effects of exercise as it pertains to the endocannabinoid system. ${ }^{2}$ Interest in the study of this system is peaking as use of cannabis and hemp-based products reaches an all-time high.

\section{Exploring the endocannabinoid system}

Within the last 25 years, the endocannabinoid system has emerged as a highly relevant and unique neuromodulatory system.
As with other neurotransmitter systems, the endocannabinoid system is comprised of the endogenous cannabinoids, their receptors, and an array of enzymes responsible for both synthesis and degradation. Endocannabinoid receptors are ubiquitous in the brain and take effect primarily in the cortex, amygdala, basal ganglia, hippocampus, hypothalamus, and cerebellum. One fascinating feature of endocannabinoids is that their precursors lie embedded within lipid membranes. Nearly on demand, endocannabinoids can be rapidly synthesized and released. This grants them almost immediate availability to get into the action at the synapse. ${ }^{2}$

One study of mice found that those who were exercised experienced improvements in anxiety behaviors and better tolerance to pain. Further, when the exercised mice were treated with endocannabinoid receptor antagonists, they remained anxious and were more sensitive to pain. Endorphin antagonists had no effect on the outcome of these tests. ${ }^{1}$ A similar study conducted in humans found improvement in subjective anxiety scores after 45 minutes of moderateintensity exercise. This study also showed no change with naltrexone administration vs placebo, again supporting the hypothesis
LET YOUR VOICE BE HEARD

CURRENT PsyChIATRY invites psychiatry residents to share their views on professional or clinical topics for publication in Residents' Voices. E-mail jbauer@mdedge.com for author guidelines. 
that endorphins play little role in this phenomenon. Interestingly, levels of endogenous cannabinoids were elevated following exercise. ${ }^{3}$ These findings suggest a possible link between activation of the endogenous endocannabinoid system and the anxiolytic properties of exercise.

For good reason, the endocannabinoid system has attracted substantial interest as a focus for a new class of drugs to treat anxiety and stressrelated disorders. It remains unknown how we can best harness its many beneficial effects in a safe and effective manner. With that said, activities such as physical exercise, mindfulness meditation, yoga, and other forms of complementary medicine are immediately available and cost-effective methods that have at least preliminary data revealing their multiple health benefits, including improvement in the symptoms of anxiety and activation of endogenous cannabinoids. ${ }^{1,-6}$

As we are all aware, medical training and practice is full of a variety of stresses and demands. Given these demands, finding a balance between mind, body, and spirit can seem like an impossible task. Besides the obvious physical benefits of regular exercise, running can serve to employ the stress-modifying effects of our endogenous cannabinoid system to reduce perceived anxiety and improve wellness. Indeed, at the start of any bout of exercise - especially running - the transition from rest can be startling. Rest assured that there is good news waiting beyond the first few miles. Your reward for patience and perseverance is a beautiful freedom experienced only by those who have earned it. The best part of it all? It is waiting for you right outside your door.

\section{References}

1. Fuss J,SteinleJ, Bindila L, et al. Arunner's high depends on cannabinoid receptors in mice. Proc Natl Acad Sci USA. 2015;112(42):13105-13108.

2. Patel S, Hill MN, Cheer JF, et al. The endocannabinoid system as a target for novel anxiolytic drugs. Neurosci Biobehav Rev. 2017;76(Pt A):56-66

3. Siebers M, Biedermann SV, Bindila L, et al. Exercise-induced euphoria and anxiolysis do not depend on endogenous opioids in humans. Psychoneuroendocrinology. 2021; 126:105173.

4. Dietrich A, McDaniel WF. Endocannabinoids and exercise. Br J Sports Med. 2004;38(5):536-541.

5. Hofmann SG, Sawyer AT, Witt AA, et al. The effect of mindfulnessbased therapy on anxiety and depression: a meta-analytic review. Journal of Consulting and Clinical Psychology. 2010;78(2):169-183.

6. Watkins BA. Endocannabinoids, exercise, pain, and a path to health with aging. Mol Aspects Med. 2018;64:68-78.
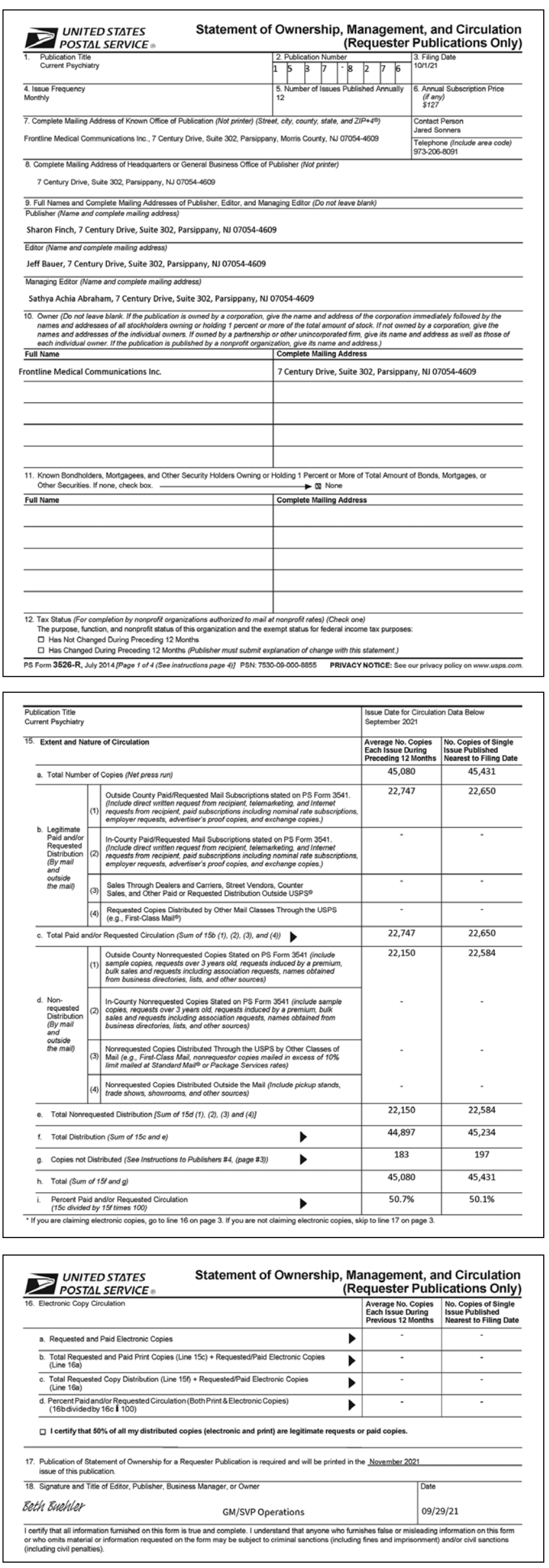